\title{
Quercetin Anti-Cancer Effect in Renal Cancer Through Regulating Survivin Expression and Caspase 3 Activity
}

\author{
Chengxian $\operatorname{Han}^{1}$, Heyan $\mathrm{Gao}^{2 *}$, Xiuwu Zhang ${ }^{3}$ \\ ${ }^{1}$ Department of Urinary Surgery, Xianyang First People's Hospital, Xianyang, \\ Shanxi 712000, P.R. China; \\ ${ }^{2}$ Department of Kidney Internal Medicine, Xianyang First People's Hospital. \\ Xianyang, Shanxi 712000, P.R. China; \\ ${ }^{3}$ Department of Radiation Oncology, University of Maryland School of \\ Medicine, Baltimore, MD 21221, USA.
}

*Corresponding Author: Heyan Gao, Email: gaoheyan0121@sina. com.

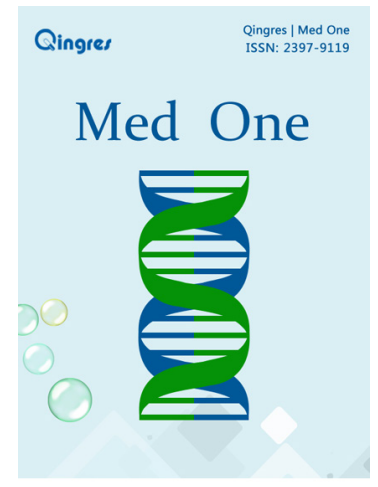

http://mo.qingres.com

\section{GOPEN ACCESS}

DOI: 10.20900/mo.20160003

Received: November 9, 2015

Accepted: January 19, 2016

Published: February 25, 2016

Copyright: (2016 Cain et al. This is an open access article distributed under the terms of the Creative Commons Attribution License, which permits unrestricted use, distribution, and reproduction in any medium, provided the original author and source are credited.

\begin{abstract}
Background: Traditional chemotherapy and radiotherapy are ineffective in the treatment of renal cancer. Quercetin exhibits a broad,spectrum anti-cancer role with only minor side effects in the treatment of many tumors, but its efficacy in renal cancer treatment is presently unknown.

Methods: Renal cancer ACHN cells were cultured and treated with quecertin at various dosages. Cell viability was tested by MTT assay. Flow cytometry measured cell apoptosis. Real time PCR and Western Blot measured survivin expression, and caspase 3 activity was also detected.
\end{abstract}

Results: Quecertin significantly suppressed ACHN cell proliferation and induced early cell apoptosis in a dose-dependent manner $(p<$ $0.05)$. Quecertin significantly enhanced caspase 3 activity $(p<0.05)$, but downregulated survivin mRNA and protein expression $(p<0.05)$.

Conclusion: Quecertin may induce renal cancer cell apoptosis by inhibiting survivin expression and activating caspase 3 .

Key Words: Quecetin; Survivin; Caspase 3; Apoptosis; Renal cancer 


\section{INTRODUCTION}

Renal cancer accounts for $2 \%$ of all adult malignancies and is the second-most common malignant tumor of the urogenital system. Renal cancer incidence is increasing in China, mainly among younger men ${ }^{[1,2]}$. Most primary renal cancers are not diagnosed until in an advanced stage as there are few typical symptoms for early diagnosis. Late diagnosis renders surgical treatments ineffective ${ }^{[3]}$. All that remains for patients with advanced renal cancer is traditional chemotherapy and radiotherapy, yet renal cancer is non-responsive to both therapies ${ }^{[4]}$. Therefore, there is still an urgent need for identifying effective treatments, along with early detection, for renal cancer remain urgently needed.

Quercetin is a hydroxyl flavonoid that can be extracted from a variety of Chinese herbal medicines, vegetables, and fruits ${ }^{[5]}$. Quercetin has various pharmacological qualities, including scavenging free radicals, reducing blood fat, antiinflammatory effects, anti-tumor effects, and antiplatelet aggregation ${ }^{[6,7]}$. Quercetin exerts anticancer roles through suppressing tumor cell growth, regulating the cell cycle, and inducing apoptosis ${ }^{[8]}$. The molecular mechanisms involved in the anticancer effect of quercetin have been reported in several types of tumors. The cytotoxic effect of quercetin on HL-60 human promyelocytic leukemia cells was associated with the rapid, and transient, induction of caspase 3/CPP32 activity ${ }^{[9]}$. Quercetin was found to block $\mathrm{H} 2 \mathrm{O} 2$-induced phosphorylation of ERK and p53 protein in rat glioma C6 cells [10]. Quercetin inhibited breast carcinoma cell invasion by suppressing PKC delta/ERK/AP-1dependent matrix metalloproteinase- 9 activation [11]. Quercetin nanoliposome-induced C6 glioma cell death has been associated with JAK2/STAT3 and mitochondrial pathways ${ }^{[12]}$. A recent study found that quercetin increases breast cancer cell sensitivity to Dox by increasing PTEN expression and subsequent Akt phosphorylation downregulation ${ }^{[13]}$. However, the anti-cancer effect of Que on renal cancer cells remains to be clarified.

A 2-year animal study demonstrated a carcinogenic activity of quercetin in the kidney, but not in other organs of the male rat ${ }^{[14]}$. A following study by Zhu and Liehr reported that quercetin increased the severity of estradiol-induced tumorigenesis in hamster kidneys ${ }^{[15,16]}$. The reevaluation of a 2-year carcinogenicity bioassay of quercetin confirmed an increase in renal tumors in male Fischer 344 rats that received mid- and highdoses of quercetin ${ }^{[17]}$. Hsieh et al. study in DM rat model for a 28-week experimental period observed significantly high incidence of renal cell carcinoma ${ }^{[18]}$. However, a recent study demonstrated that quercetin can reduce cisplatin nephrotoxicity in rats without compromising its anti-tumor activity ${ }^{[19]}$. Liu et al. study revealed that a combination of quercetin and hyperoside induced cytotoxicity in 786-O renal cancer cells through inducing caspase-3 and PARP cleavage ${ }^{[20]}$. Meng et al. study observed that quercetin suppressed cell proliferation and migration, and induced cell cycle arrest and apoptosis in Caki2 renal cell carcinoma cells ${ }^{[21]}$. However, the function and mechanism of quercetin on renal cancer apoptosis still needs to be elucidated.

In this study, the apoptotic effect of quercetin was tested in human renal cell adenocarcinoma cells and the effects of quercetin on the expression of survivin and activity of caspase- 3 were measured.

\section{MATERIALS AND METHODS}

\subsection{Main reagents}

RPMI-1640 medium, FBS, and penicillinstreptomycin were purchased from Hyclone (Logan, UT, USA). MTT was purchased from Gibco (Grand Island, NY, USA). PVDF membrane was purchased from Pall Life Science (Port Washington, NY, USA). ECL reagents were purchased from Amersham Biosciences. Rabbit anti-human survivin primary antibody and HRP-conjugated IgG secondary antibody were purchased from Cell Signaling Technology (Danvers, MA, USA). Caspase 3 activity kit was purchased from Pall Life Sciences. Annexin V-FITC apoptosis detection kit was purchased from BD BioScience (Sparks, MD, USA).

\subsection{Cell culture}

Human renal cell adenocarcinoma cell line was purchased from ATCC (American Type Culture Collection). ACHN cells were cultured in RPMI-1640 medium containing $10 \% \mathrm{FBS}, 100 \mathrm{U} / \mathrm{ml}$ penicillin, and $100 \mu \mathrm{g} / \mathrm{ml}$ streptomycin at $37^{\circ} \mathrm{C}, 5 \% \mathrm{CO}_{2}$.

\subsection{MTT assay}

ACHN cells in logarithmic phase were seeded in a 96-well plate at $3.0 \times 10^{3}$ cells/well for overnight. 
The cells were treated with $0 \mu \mathrm{M}, 20 \mu \mathrm{M}$, and 40 $\mu \mathrm{M}$ quercetin for $48 \mathrm{hrs}$. Twenty $\mu \mathrm{L}$ of MTT $(5 \mathrm{~g} / \mathrm{L})$ was added to each well. After incubation for $4 \mathrm{hrs}$ at $37^{\circ} \mathrm{C}$, the supernatant was removed and $150 \mu \mathrm{L}$ of DMSO was added and the plate was gently shaken for $10 \mathrm{~min}$ at room temperature (RT). The plate was read at $570 \mathrm{~nm}$ wavelength. The proliferation rate was calculated. The experiment was repeated for at least three times.

\subsection{Flow cytometry}

The cells were seed in a $50 \mathrm{ml}$ culture flask at $5 \times$ $10^{5}$ cells $/ \mathrm{mL}$ and the cells in logarithmic phase were treated with $0 \mu \mathrm{M}, 20 \mu \mathrm{M}$, and $40 \mu \mathrm{M}$ Que for 48 hrs. Cells were then collected and washed with $1 \times$ PBS. After centrifugation at $1000 \mathrm{rpm}$ for $5 \mathrm{~min}$, the cells were fixed in pre-cooled $75 \%$ ethanol at $4^{\circ} \mathrm{C}$ overnight. After removing the ethanol and washing with $1 \times$ PBS, the cells were resuspended in $800 \mu \mathrm{l} 1$ $\times$ PBS with $1 \%$ BSA. After the addition of $100 \mu \mathrm{g} / \mathrm{ml}$ PI solution (3.8\% Sodium Citrate, pH7.0) and 100 $\mu \mathrm{L}$ RNAse $\mathrm{A}(10 \mathrm{mg} / \mathrm{ml})$ at $37^{\circ} \mathrm{C}$ for $30 \mathrm{~min}$ in the dark, the cells were tested by flow cytometry. The data was analyzed by FCSExpress 3.0 software.

\subsection{Caspase 3 activity detection}

Caspase 3 activity was measured according to the manufacturer's protocols. The cells were treated as above, digested by enzyme, and centrifuged at 600 $\mathrm{g}$ for $5 \mathrm{~min}$ at $4^{\circ} \mathrm{C}$. The cells were then incubated with RIPA buffer on ice for $15 \mathrm{~min}$ and centrifuged at $20,000 \mathrm{~g}$ at $4^{\circ} \mathrm{C}$ for $5 \mathrm{~min}$ to remove debris. After adding $2 \mathrm{mM}$ Ac-DEVD-pNA, the cell lysate was tested at $405 \mathrm{~nm}$ to calculate caspase 3 activity.

\subsection{Real time PCR}

Total RNA was extracted from ACHN cells using Trizol reagents and reverse transcribed to cDNA according to the user manual. The primers used in the experiment are listed in Table 1. Real time PCR was run for $55^{\circ} \mathrm{C}, 1 \mathrm{~min}$, followed by 35 cycles of $92^{\circ} \mathrm{C}, 30 \mathrm{~s}, 58^{\circ} \mathrm{C}, 45 \mathrm{~s}$, and $72^{\circ} \mathrm{C}, 35 \mathrm{~s}$. GAPDH was amplified as internal control. Relative gene expression was analyzed by the $2^{-\mathrm{Ct}}$ method.

Table 1. Primer sequence

\begin{tabular}{lll}
\hline Gene & Forward, $\mathbf{5}^{\prime}$-3' & Reverse, $\mathbf{5}^{\prime}$-3' \\
\hline GADPH & ACCAGGTATCTGCTGGTTG & TAACCATGATGTCAGCGTGGT \\
Survivin & GACTCTGTCCCAGTCCCAT & GCCTGGATTACATTAGCTATT \\
\hline
\end{tabular}

\subsection{Western blot}

The treated ACHN cells were incubated with RIPA buffer on ice for $15 \sim 30 \mathrm{~min}$. The cells were then ultrasonicated at $4 \times 5$ s and centrifuged at $10,000 \times$ $\mathrm{g}$ for $15 \mathrm{~min}$ at $4^{\circ} \mathrm{C}$. The supernatant was stored at $-20^{\circ} \mathrm{C}$. The protein was separated on $10 \%$ SDSPAGE gel and transferred to PVDF membranes. After blocking with $1 \times$ PBST buffer containing $5 \%$ skim milk for 2 hrs, the membranes were incubated with survivin primary antibody (1:1000 dilution) overnight at $4^{\circ} \mathrm{C}$. After washing with $1 \times$ PBST buffer, the membranes were further incubated with secondary antibody (1:2000) at RT for 30 min. The membranes were then incubated with chemiluminescent agent for $1 \mathrm{~min}$ and exposed to X-ray film $\mathrm{s}$. The densities of protein bands were scanned using Protein image processing system and analyzed using Quantity one software. All experiments were repeated four times ( $\mathrm{n}$ $=4)$.

\subsection{Statistical analysis}

Data were analyzed using SPSS16.0 software and presented as mean \pm standard error $( \pm S)$. One-way ANOVA was used for comparison analysis. A $p<0.05$ was considered as statistically significant.

\section{RESULTS}

\subsection{Quercetin inhibited ACHN cell proliferation}

MTT assay showed that quercetin significantly inhibited ACHN tumor cell proliferation compared to untreated control cells $(p<0.05) .40 \mu \mathrm{M}$ quercetin showed a more obvious suppressive effect than $20 \mu \mathrm{M}$ quercetin $(p<0.05)$. This suggested that quercetin dose-dependently inhibited renal cancer cell proliferation (Fig. 1). 


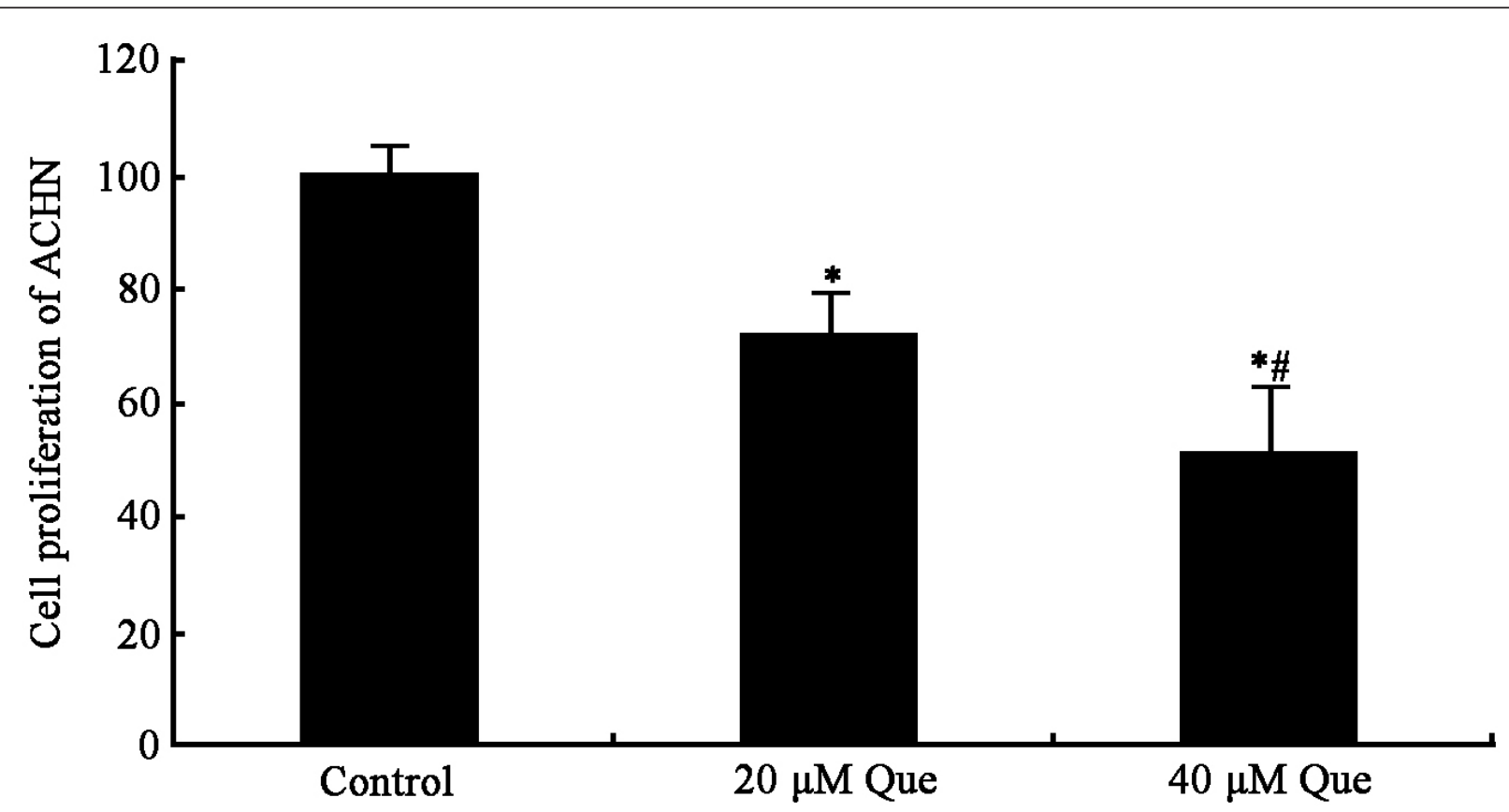

Fig. 1 Que inhibits cell proliferation in ACHN cells. ${ }^{*} p<0.05$ vs. control; $\# p<0.05$ vs. cells treated with $20 \mu \mathrm{M}$ Que. $N=3$.

Flow cytometry assay showed that quercetin induced significant apoptosis in ACHN cells compared to untreated cells $(p<0.05) .40 \mu \mathrm{M}$ quercetin exhibited more obvious effect than 20 $\mu \mathrm{M}$ quercetin $(p<0.05)$, suggesting that quercetin can induce renal cancer cell apoptosis in a dosedependent manner (Fig. 2A, 2B).
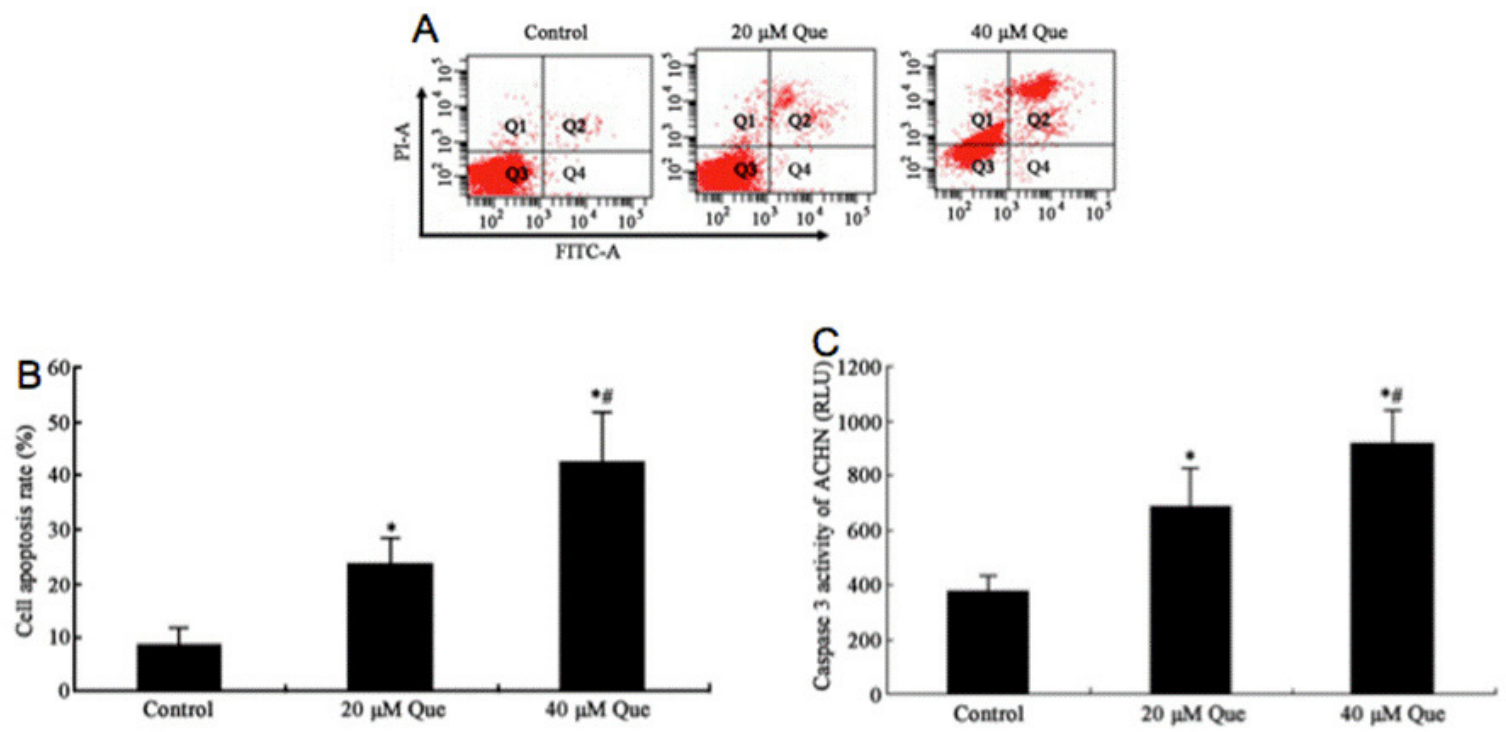

Fig. 2 Que induced cell apoptosis inACHN cells. A) Representative of flow cytometry assay. B) Percentage of apoptotic cells. C) Que increased caspase 3 activity in ACHN cells. ${ }^{*} p<0.05$ vs. control; $\# p<0.05$ vs. cells treated with $20 \mu \mathrm{M}$ Que. $\mathrm{N}=4$. 
After treatment with different concentrations of quercetin for $48 \mathrm{~h}$, caspase 3 activity was detected. quercetin significantly increased caspase 3 activity compared to untreated control cells $(p<0.05) .40 \mu \mathrm{M}$ quercetin showed more obvious effect than $20 \mu \mathrm{M}$ quercetin $(p<0.05)$, suggesting a dose-dependent effect of quercetin on caspase 3 activity (Fig. 2C).

Real time PCR revealed that quercetin treatment significantly suppressed survivin mRNA and protein expression ( $p<0.05)$. $40 \mu \mathrm{M}$ quercetin showed a more obvious effect on survivin mRNA and protein expression than $20 \mu \mathrm{M}$ quercetin (Fig. 3).
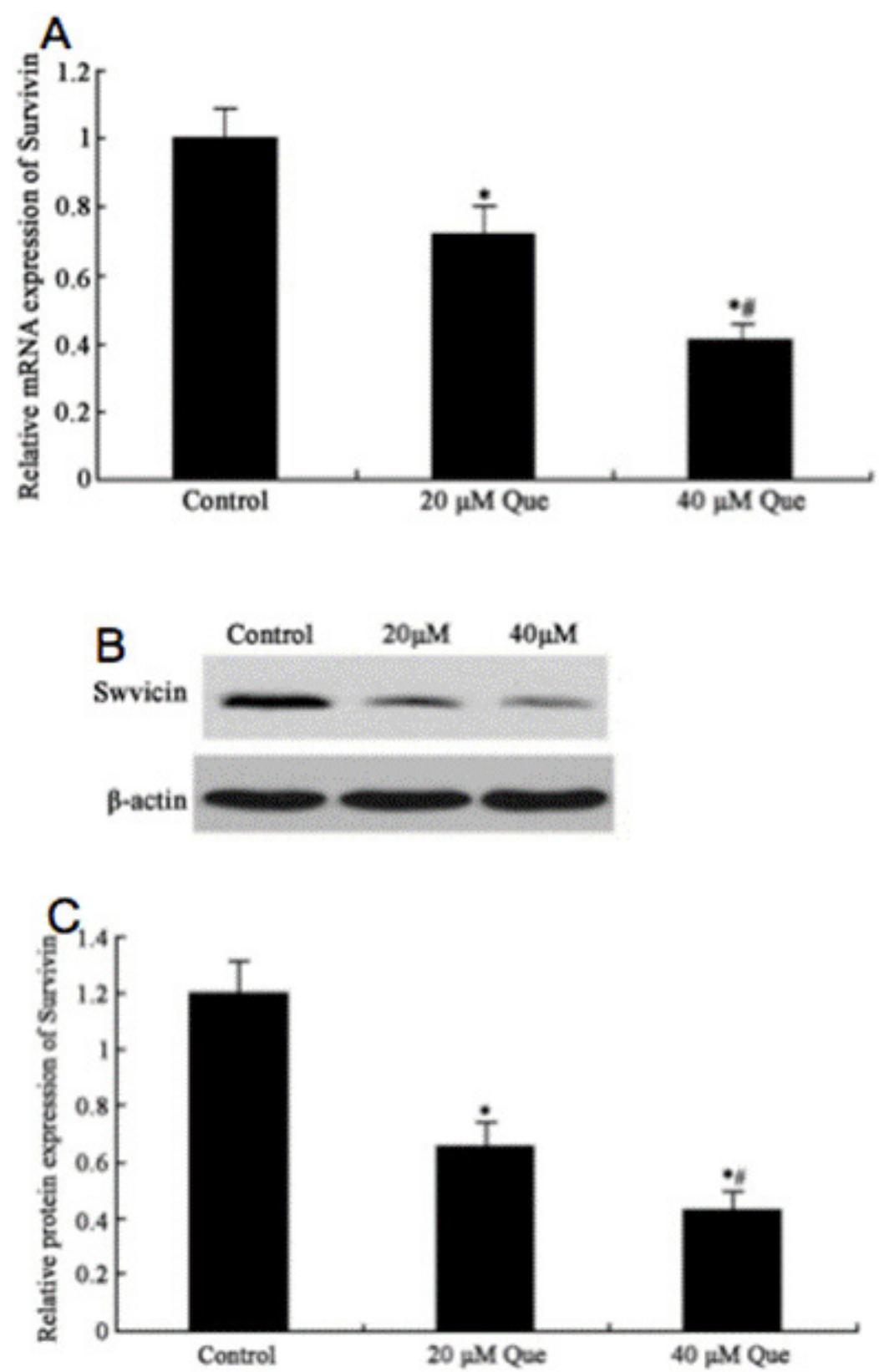

Fig. 3 Que inhibited Survivin mRNA and protein expression in ACHN cells. A) Real-time PCR of survivin mRNA expression. * $p<0.05$ vs. control; $\# p<0.05$ vs. cells treated with $20 \mu \mathrm{M}$ Que. $\mathrm{N}=4$. B) Representative Western blot of survivin protein expression in ACHN cells. C) Semi-quantitative analysis of survivin protein expression in Western blot. ${ }^{*} p<0.05$ vs. control; $\# p<0.05$ vs. cells treated with $20 \mu \mathrm{M}$ Que. $N=4$. 


\section{DISCUSSION}

Although medical technology is constantly advancing, patients with renal cancer still have poor prognosis. Besides renal cancer being frequently diagnosed at the advanced stage, renal cancer cells are also not sensitive to traditional chemo and radiotherapy, which is the main cause of treatment failure. Although the anti-cancer effects of quercetin have been widely reported in a variety of cancer cells, the effect of quercetin in renal cancer cells remain uncertain. The early studies observed a carcinogenic activity of quercetin in the kidneys of animals ${ }^{[14-18]}$. While several studies have reported the anti-cancer effects of quercetin in other cancer cells, few recent studies have reported the anticancer effect of quercetin in renal cancer cells ${ }^{[19-21]}$. This study demonstrated that quercetin significantly inhibited cell proliferation and induced apoptosis in human renal cell adenocarcinoma cells. Quercetin exerted an apoptotic effect through inhibiting survivin mRNA and protein expression and activating caspase 3 .

Quercetin is a naturally occurring flavonoid and can be extracted from food and plants. Quercetin was found to play anti-tumor effects through regulating tumor cell proliferation and apoptosis ${ }^{[22]}$. Moreover, quercetin can specifically kill tumor cells with high selectivity and low toxicity to normal cells. Thus, quercetin can overcome the side effects of traditional antitumor drugs. Currently, quercetin has entered clinical trial as an anti-tumor agent ${ }^{[23]}$. Since renal cancer is resistant to current antitumor drugs, finding new drugs to treat renal cancer with high efficiency but with a small amount of side effects has is an important area of research. However, there are few studies about the role of quercetin in renal cancer. This study confirmed quercetin's anticancer effect in renal cancer cells through inhibiting proliferation and inducing cancer cell apoptosis.

Caspase 3 is a one of the major regulatory factors of apoptosis activity. Previous studies have revealed that quercetin can induce tumor cell apoptosis through increasing caspase 3 activity in liver cancer, nasopharyngeal carcinoma, and lung cancer ${ }^{[24,25]}$. Survivin is an anti-apoptosis protein that can inhibit cell apoptosis and promote cell division. Survivin is highly expressed in many tumor tissues and inhibits caspase 3 activity in tumor cells through suppressing the release of mitochondrial cytochrome C. Also, survivin can restrain the hydrolytic effect of caspase 3 on spindles and maintain cell integrity during mitosis, leading to inhibition of apoptosis and drug resistance ${ }^{[26]}$. This study showed that quercetin inhibited survivin mRNA and protein expression, and enhanced caspase 3 activity, which may be associated with quercetin-induced apoptosis in renal cancer cells.

In conclusion, quercetin induced renal cancer cell apoptosis possibly through inhibiting survivin expression and caspase 3 activation.

\section{CONFLICT OF INTERESTS}

The authors declare that they have no conflict of interests.

\section{REFERENCES}

1. Winer AG, Motzer RJ, Hakimi AA. Prognostic biomarkers for response to vascular endothelial growth factor-targeted therapy for renal cell carcinoma. Urol Clin North Am. 2016; 43: 95104.

2. Bai Q, Liu L, Long Q, Xia Y, Wang J, Xu J, Guo J. Decreased expression of mucin 18 is associated with unfavorable postoperative prognosis in patients with clear cell renal cell carcinoma. Int J Clin Exp Pathol. 2015; 8: 11005-11014.

3. Campbell L, Jasani B, Griffiths DF, Gumbleton M. Phospho-4e-BP1 and elF4E overexpression synergistically drives disease progression in clinically confined clear cell renal cell carcinoma. Am J Cancer Res. 2015; 5: 2838-2848.

4. Chen M, Xu B, Liu N, Jiang H, Wang Y, Yang $Y$, Zhang X, Sun C, Liu J, Zhu W, Chen S. Precise control of caval and hepatic vessels: Surgical technique to treat level III caval thrombus concomitant to renal cell carcinoma. Can Urol Assoc J. 2015; 9: E808-E813.

5. Sun L, Li E, Wang F, Wang T, Qin Z, Niu S, Qiu C. Quercetin increases macrophage cholesterol efflux to inhibit foam cell formation through activating PPARgamma-ABCA1 pathway. Int J Clin Exp Pathol. 2015; 8: 10854-10860.

6. Peredo-Escarcega AE, Guarner-Lans V, PerezTorres I, Ortega-Ocampo S, Carreon-Torres E, Castrejon-Tellez V, Diaz-Diaz E, Rubio-Ruiz ME. The combination of resveratrol and quercetin attenuates metabolic syndrome in rats by modifying the serum fatty acid composition and by upregulating SIRT 1 and SIRT 2 expression in white adipose tissue. Evid Based Comp Alternat Med. 2015; 2015: 474032. 
7. Jung HG, Kim HH, Paul S, Jang JY, Cho YH, Kim HJ, Yu JM, Lee ES, An BJ, Kang SC, Bang BH. Quercetin-3-O-beta-d-glucopyranosyl-(1 $\rightarrow$ 6)-beta-d-glucopyranoside suppresses melanin synthesis by augmenting p38 MAPK and CREB signaling pathways and subsequent CAMP down-regulation in murine melanoma cells. Saudi J Biol Sci. 2015; 22: 706-713.

8. Li Y, Zhou S, Li J, Sun Y, Hasimu H, Liu R, Zhang T. Quercetin protects human brain microvascular endothelial cells from fibrillar -amyloid-induced toxicity. Acta Pharm Sin B. 2015; 5: 47-54.

9. Shen SC, Chen YC, Hsu FL, Lee WR. Differential apoptosis-inducing effect of quercetin and its glycosides in human promyeloleukemic HL-60 cells by alternative activation of the caspase 3 cascade. J Cell Biochem. 2003; 89: 1044-1155.

10. Chen TJ, Jeng JY, Lin CW, Wu CY, Chen YC. Quercetin inhibition of ROS-dependent and -independent apoptosis in rat glioma C6 cells. Toxicol. 2006; 223: 113-126.

11. Lin C, Hou W, Shen S, Juan S, Ko CH, Wang L, Chen Y. Quercetin inhibition of tumor invasion via suppressing PKC delta/ERK/AP-1-dependent matrix metalloproteinase- 9 activation in breast carcinoma cells. Carcinogenesis. 2008; 29: 1807-1815.

12. Wang G, Wang J, Chen X, Du S, Li D, Pei $Z$, Lan $H$, Wu L.. The JAK2/STAT3 and mitochondrial pathways are essential for quercetin nanoliposome-induced C6 glioma cell death. Cell Death Dis. 2013; 4: e746.

13. Li SZ, Qiao SF, Zhang JH, Li K. Quercetin increase the chemosensitivity of breast cancer cells to doxorubicin via PTEN/Akt pathway. Anticancer Agents Med Chem. 2015; 15: 11851189.

14. Dunnick JK, Hailey JR. Toxicity and carcinogenicity studies of quercetin, a natural component of foods. Fundam Appl Toxicol. 1992; 19: 423-431.

15. Zhu BT, Liehr JG. Quercetin increases the severity of estradiol-induced tumorigenesis in hamster kidney. Toxicol Appl Pharmacol. 1994; 125: 149-158.

16. Zhu BT, Liehr JG. Inhibition of catechol O-methyltransferase-catalyzed O-methylation of 2- and 4-hydroxyestradiol by quercetin. Possible role in estradiol-induced tumorigenesis. J Biol Chem. 1996; 271: 1357-1363.
17. Hard GC, Seely JC, Betz LJ, Hayashi SM. Re-evaluation of the kidney tumors and renal histopathology occurring in a 2-year rat carcinogenicity bioassay of quercetin. Food Chem Toxicol. 2007; 45: 600-608.

18. Hsieh CL, Peng C, Cheng Y, Lin L, Ker YB, Chang C, Chen K, Peng R. Quercetin and ferulic acid aggravate renal carcinoma in long-term diabetic victims. J Agric Food Chem. 2010; 58: 9273-9280.

19. Sanchez-Gonzalez PD, Lopez-Hernandez FJ, Perez-Barriocanal F, Morales AI, Lopez-Novoa JM. Quercetin reduces cisplatin nephrotoxicity in rats without compromising its anti-tumour activity. Nephrol Dial Transplant. 2011; 26: 34843495.

20. Li W, Liu M, Xu YF, Feng Y, Che JP, Wang GC, Zheng J. Combination of quercetin and hyperoside has anticancer effects on renal cancer cells through inhibition of oncogenic microRNA-27a. Oncol Rep. 2014; 31: 117-124.

21. Meng FD, Li $Y$, Tian $X$, Ma $P$, Sui CG, Fu LY, Jiang $Y$. Synergistic effects of snail and quercetin on renal cell carcinoma Caki-2 by altering AKT/ mTOR/ERK1/2 signaling pathways. Int J Clin Exp Pathol. 2015; 8: 6157-6168.

22. Lee S, Oh DG, Lee S, Kim GR, Lee JS, Son YK, Bae CH, Yeo J, Lee CH. Chemotaxonomic metabolite profiling of 62 indigenous plant species and its correlation with bioactivities. Molecules. 2015; 20: 19719-19734.

23. Taslidere E, Dogan Z, Elbe H, Vardi N, Cetin A, Turkoz Y. Quercetin protection against ciprofloxacin induced liver damage in rats. Biotech Histochem. 2015; 91(2): 116-121.

24. Liao H, Bao X, Zhu J, Qu J, Sun Y, Ma X, Wang E, Guo X, Kang Q, Zhen Y. O-Alkylated derivatives of quercetin induce apoptosis of MCF-7 cells via a caspase-independent mitochondrial pathway. Chem Biol Interact. 2015; 242: 91-98.

25. Hu J, Yu Q, Zhao F, Ji J, Jiang Z, Chen X, Gao P, Ren Y, Shao S, Zhang L, Yan M. Protection of quercetin against triptolide-induced apoptosis by suppressing oxidative stress in rat Leydig cells. Chem Biol Interact. 2015; 240: 38-46.

26. Pandey A, Vishnoi K, Mahata S, Tripathi SC, Misra SP, Misra V, Mehrotra R, Dwivedi M, Bharti AC. Berberine and curcumin target survivin and STAT3 in gastric cancer cells and synergize actions of standard chemotherapeutic 5-fluorouracil. Nutr Cancer. 2015; 67: 12931304. 